\title{
Study on the E-commerce Logistics Innovation and Traditional Logistics Transformation under Internet Thinking
}

\author{
Lihua Chen
}

Shandong Xiehe University, Jinan, Shandong, 250107

Keywords: E-commerce logistics innovation; Internet thinking; traditional logistics transformation

\begin{abstract}
The user demand and industrial development model in the Internet era have undergone earth-shaking changes, especially the industrial development model formed on the basis of Internet thinking, and it is very different from the traditional e-commerce logistics model. This paper discusses the unique ways and characteristics of e-commerce logistics innovation under the Internet thinking and the advantages and development necessity compared with traditional logistics. On this basis, it puts forward a relatively reasonable e-commerce logistics innovation and traditional logistics transformation measures and methods.
\end{abstract}

\section{Introduction}

The development of traditional logistics can be traced back to the era of China's planned economic system, adapting to the shortage of materials during the planned economic system and the sale or distribution of goods according to plan. Therefore, what is needed is the production, packaging and transportation in the traditional logistics mode. To the unified mode of warehousing, this method can strengthen the process management of products to some extent and the effective management of goods under special circumstances. Since the reform and opening up, the development of logistics has encountered the impact of changes in the specific needs of the people and the impact of the market economic system. There has been a certain backlog of commodities and overcapacity.

\section{Reform and opening up to the logistics development in the Internet age}

Since the reform and opening up, commodity logistics has gradually begun to be managed by enterprises. Therefore, a large number of small batches and batches have been formed in the specific logistics management process, and consumers' demand for goods purchase is very diverse. In many cases, it will pursue the customization and uniqueness of the products. Therefore, in the sales and logistics management of certain special commodities, it will face too much logistics distribution and delivery of single commodities. It is worth noting that the development of science and technology in the Internet era is to some extent solving the problems in the management of commodity logistics. Although after the reform and opening up, the economic system and user demand have undergone great changes, enterprises have expanded more channels and added more ways to manage and manage commodity logistics, but the specific model method is still in accordance with traditional logistics. The usual practice is to use the order for deployment and transportation as well as warehousing. Due to the high cost of logistics and distribution of a single commodity in logistics, there will be a high logistics cost in the traditional transportation mode, and the logistics management in the business operation and development process belongs to the direct management of the enterprise. The incurred costs will be reflected in the final sale price of the goods or the main business cost of the business management. Therefore, it is necessary to have a relatively independent department or enterprise to carry out specialized logistics management to share the operating pressure of the main production products. In the middle of the reform and opening up, this specialized logistics management outsourcing company appeared [1].

In fact, logistics outsourcing presents a lack of system management factors in the absence of Internet technical support. In many cases, transportation and logistics rely on telephone notifications 
and written documents, while telephone notifications are accurate in information transmission and document retention. The rigor is not able to meet the professional business management requirements, but the way of telephone notification occupies a professional position of efficiency and speed in traditional logistics management. In many cases, the written documents cannot meet the urgency and efficiency of logistics transportation. Therefore, the traditional logistics management lacks the technology and mode that can fully integrate the logistics outsourcing business smoothly. The emergence of Internet technology has solved this thorny problem. It embodies rigor and comprehensiveness in file storage and retention. The notification when the business occurs is also relatively fast, so that many businesses can fully adjust the animal flow in a limited time. Personnel and vehicles in management, as well as cargo distribution equipment, etc. [2]. The emergence of the Internet model is a supplement to the development of logistics management, but in many cases it is an opportunity to provide change, and can use Internet technology to meet real-time online deployment and logistics tracking management, and more able to connect to users. To provide real-time logistics information, the relationship between the user and the merchant is completely completed, and the delivery intermediary in the logistics process is more clearly presented, so that the user can feel the continuous transmission and transportation of the goods, and can also obtain certain A sense of security and satisfaction.

\section{The exploration of e-commerce logistics innovation mode under the Internet thinking}

The e-commerce logistics under the Internet thinking meets the specific Internet users and individuals. In many cases, the information provided by the goods needs to provide services through proper communication, so that users can feel the specific form and characteristics of the products online, and pass Detailed communication and information browsing to determine if you need to purchase this item. However, there are certain problems in e-commerce logistics under the Internet thinking, which is the long-distance hindrance of communication with users. Although it is possible to use online text and voice communication to obtain product information and logistics information, in many cases it is impossible to control whether the change of information can adapt to specific user needs [3].

Under the Internet thinking, the user's needs are also characterized by diversification and richness. At this time, if there is a lack of prior knowledge of the user and the appropriateness of the special problem processing, problems will arise in the process of satisfying many special needs. Not only will the loss of merchants and logistics distribution service personnel and work points, but also affect the specific consumption experience to a certain extent. The information dissemination of the unsatisfactory consumer experience presents a fast-paced communication feature in the Internet era, and it also affects other consumer desires and consumption decisions that affect the choice of goods and logistics service choices. .

Connecting the communication bridge with users is the key to innovation. In the existing form, it is necessary to find that the customer service established by the e-commerce logistics platform is a professional innovation mode to a certain extent. Innovation on this basis requires the inherent strengthening of management of this model, and it is necessary to convey the relationship between universality and particularity in logistics services to the whole society. In general, it can be considered that the logistics service staff is dereliction of duty, and in some cases it is derived from the unreasonable management system. It should also make the users clear that the specific delivery is not timely enough and not because of the dereliction of duty of all employees. In many cases, the e-commerce logistics platform and the user need to establish a professional service agreement and confirmation within the controllable range to avoid complete the user. The idealized promise is denied when the promise is not completed. It is also necessary to establish a complete and perfect after-sales service system, so that users are willing and inclined to express their experience in the experience of logistics services, and can enable users to reduce the emotional venting in the evaluation of logistics service business and more purely evaluate the professionalism of the business itself. Sex.

Emotional complaints and service attitude complaints in the e-commerce service platform 
occupy an important proportion of the complaints. In many cases, the professional quality of the logistics service personnel itself is insufficient, and the quality of the users themselves is not enough. ]. In this case, it is actually a social problem to develop the innovation of close contact with users. In many cases, e-commerce logistics enterprises are a platform to potentially improve the emotional expression of the public and the rational expression of appeal. It is also inevitable to assume this part of the social responsibility.

Therefore, from the social point of view, this part of the model innovation reflects the innovation of social civilization outside the technology, can help the people to calmly express the idealized mode of appeal, and the innovative way lies in the cultivation of employees' self-cultivation and artificial intelligence. The introduction of technology and the updating of e-commerce platform algorithms and procedures have enabled users to have more room to promote the expression of true claims.

The opening of the media platform in the Internet era has made the communication between merchants and logistics and users and logistics more convenient, and to a certain extent, reduced the information in the traditional logistics mode. And the introduction of big data technology and the improvement of related technologies such as cloud computing and mobile internet enable the connection between merchants and logistics to reduce a large amount of costs and costs, and also apply these costs and costs to the continuous updating and development of technology. The most noteworthy part of this part is that the cooperation between the merchant and the logistics platform has reached a close connection and mutual dependence. The merchant provides the essential content of logistics, and the logistics platform provides the smooth flow of channels and the real reach of users. To transfer value, from the perspective of the process of delivery, logistics services provide timely delivery as material content, while what needs to be innovated is the information delivery service established following the timely delivery of real information. At this point, it is able to bring The integrated marketing communication of the user's consumption experience, the user feels the result of the integrated business service and logistics service, so the merchant and the logistics service platform are in a state of mutual development. However, the degree of understanding and cognition of the user's own consumption behavior is that the business has more advantages.

User images obtained based on such data information need to establish certain privacy protection of user data information. From the perspective of legal and ethical regulations, this behavior is a data information service that needs to be supervised and managed. The user data information held by the logistics service also has relatively more private data information. Therefore, on the basis of mutual cooperation, it is necessary to avoid leakage of user privacy data, and also needs to work together based on the joint efforts of enterprises and enterprises. In the process, consciously assume the information obligation to protect users and consumers, which is the institutional innovation in the content of laws and ethics regulations.

The more in-depth service for users and consumers lies in the control of preferences and the control of the communication methods that are keen. Users will keep certain traces in the content browsing process and will also present in the process of information exchange with merchants. Self-like preferences, in the process of information service to users need to establish a summary of the preference, but also need to improve the algorithm program based on big data. Not only do you need to make similar suggestions based on user preferences, but you also need to remind users to pay attention to areas that have not been involved in order to provide a certain freshness [5]. In this case, the logistics platform needs to cooperate deeply with the merchant to obtain the connection of the user requirements, so that the specific needs of the user can be repeated without repeated emphasis.

The business in the traditional logistics service exists in the commodity service enterprise. Although it is a large management cost, it has certain advantages in the overall operation of the enterprise. The management of modern logistics enterprises has seen the advantages of the traditional mode. For example, the distribution services and warehouse management of Jingdong enterprises make the links of product distribution and logistics information more smooth, and can not only take advantage of the rapid advantages of Internet information transmission, but also make 
better use of The distribution and warehousing services directly under the enterprise reduce the intermediate links. Therefore, the service concept of the logistics enterprise management and management is to reduce the operating costs by reducing the intermediate links, and spend more on the products themselves and technology. On the update.

The development of logistics is not only a single form of never change, any era and any economic conditions have a business model that is relatively adapted to the development of the times, and the essence of innovation is the preservation of high-quality models in the current society and the unreasonable way. The denial, at this point, the enterprise's reuse of the direct distribution model is an innovation in the development of logistics.

Of course, in the current society, the status of direct distribution of e-commerce platforms needs to be supported by a larger capital chain and value chain. More logistics companies are looking for a way to achieve business innovation. Taking SF Logistics as an example, it has shown its leading position in the innovation of internal business management. It can use the rich transportation and speed of transportation to establish a competitive advantage different from other logistics companies, and it has also established a relatively stable and A reasonable logistics service brand.

The number of logistics service enterprises in the current society is very rich, but in many cases, it is impossible to distinguish the business priorities, which makes the competition within the industry lack certain order. Therefore, at this point, the logistics enterprises need to establish themselves differently from other enterprises. Advantages [6]. The e-commerce logistics under the Internet technology also shows the connection with the users in the "last mile". At this point, we can see the demand exploration and innovation of the rookie network and other related enterprises, the construction of the rookie station and the self-reporting cabinet and the professional The logistics and distribution information integration service enables users to have the space to choose the delivery time of express goods, so as to improve the logistics management innovation of "last mile”.

\section{Conclusion}

Compared with traditional logistics methods, modern logistics development has experienced the upgrading of the degree of specialization of outsourcing business after the reform and opening up and the transformation of logistics methods under the influence of the Internet. The establishment of the logistics platform enables users and merchants as well as the logistics service center to establish a relatively complete communication platform. In communication and communication, it is necessary for the logistics enterprise to undertake the corresponding social system to improve its own responsibilities and to work with the merchants to improve the industry regulations. On the basis of technological innovation, it will increase service innovation for business management and continuously develop more potential social needs and management needs.

\section{References:}

[1] Sa Rina. Analysis on the Application of "Internet +" in E-commerce Logistics Distribution Information System [J]. Logistics Science and Technology, 2016, 39(12):46-47.

[2] Zhu Shaoping, Hu Mengwen. Research on "Internet + E-commerce Logistics" System Based on Social System Research Method [J]. Shopping Mall Modernization, 2015(14): 35-37.

[3] Zhao Jing. Problems and Solutions to the Development of E-commerce Logistics in the Age of "Internet +"[J].Logistics Technology, 2015, 34(20): 191-192+211.

[4] Shi Na. Analysis on the Status Quo and Trend of Mobile E-commerce Logistics Development [J].Information and Communication Technology, 2015, 9(04):42-46.

[5] Li Guanyi. Internet Thinking on the Re-innovation of E-commerce Logistics and Traditional Logistics Transformation-Thinking Based on Value Connection[J].Science and Technology Management Research,2016,36(18):171-175.

[6] Zhan Bin, Gu Qiqi, Li Yang. Optimization of the "last mile" distribution mode of e-commerce logistics under the background of “Internet +"[J].Logistics Technology,2016,35(01):1-4+11. 